\title{
INTEGRAÇÃO DE BIOVIDRO EM MATRIZES DE HIDROGEL DE CELULOSE BACTERIANA
}

\author{
C. SCHROEDER ${ }^{1,2}$, J. BORTUZZO ${ }^{2}$, L. M. PORTO ${ }^{1}$, A.R. BOCCACCINI ${ }^{2}$ \\ ${ }^{1}$ Universidade Federal de Santa Catarina, \\ Departamento de Engenharia Química e Engenharia de Alimentos - \\ Integrated Technologies Laboratory (InteLab) \\ E-mail: \{camila, luismar\}@intelab.ufsc.br \\ ${ }^{2}$ University of Erlangen-Nuremberg, \\ Department of Materials Science and Engineering - \\ Institute for Biomaterials (WW7) \\ E-mail: judith.a.bortuzzo@fau.de, aldo.boccaccini@ww.uni-erlangen.de
}

\begin{abstract}
RESUMO - Biomateriais osteointegráveis para substituição e/ou regeneração de tecidos ósseos constituem importantes desenvolvidos de engenharia de tecidos, devido à sua grande demanda e pela vantagem de substituírem enxertos de origem animal. Micropartículas de biovidro (45S5 Bioglass ${ }^{\circledR}$, Alemanha) de tamanho médio igual a 2,0 $\mu \mathrm{m}\left(1 \mathrm{~g} \cdot \mathrm{L}^{-1}\right)$ foram suspensas juntamente com membranas circulares de celulose bacteriana (CB), em água destilada por agitação a $360 \mathrm{rpm}$ e temperatura ambiente, durante 24 horas, visando sua integração à matriz do hidrogel de CB. As amostras foram analisadas quanto à sua resistência mecânica, difração de raios X, espectroscopia de infravermelho com transformada de Fourier, microscopia eletrônica de varredura. Os resultados foram comparados com membranas de celulose pura. Obteve-se dispersão homogênea e fixação das micropartículas de biovidro, encapsuladas no interior do hidrogel, nunca anteriormente relatada. Este é um material implantável e de grande biocompatibilidade.
\end{abstract}

\section{INTRODUÇÃO}

A engenharia de tecidos é um campo em crescimento, o qual tem como objetivo desenvolver substitutos biológicos que possam restaurar e/ou melhorar as funções de tecidos e órgãos (Langer e Cavalcanti, 1993; Chan e Mooney,2008). Os materiais mais utilizados para scaffolds em engenharia de tecidos são polímeros naturais ou sintéticos, tais como polissacarídeos, hidrogéis ou elastômeros termoplásticos (Mano et al., 2004; Drotleff et al., 2004). Outras categorias importantes desses materiais são cerâmicas bioativas como fosfatos de cálcio e vidros bioativos. Atualmente os compósitos de polímeros e cerâmicas estão sendo desenvolvidos com o intuito de aumentar a estabilidade e melhorar a interação de tecidos duros (Kim et al., 2004).

A celulose bacteriana (CB) produzida pelas bactérias do gênero Gluconacetobacter possui propriedades peculiares tanto químicas quanto físicas. É um biopolímero que, na forma de hidrogel, mimetiza a matriz extracelular in vitro. A CB vem sendo estudada especificadamente como uma estrutura para regeneração de tecidos cartilaginosos e apresenta características promissoras como sua rede de nanofibras, alta hidrofilicidade, resistência à tensão, biocompatibilidade e moldabilidade in situ (Svensson et al., 2005). 
O desenvolvimento produtos de engenharia de tecidos ósseos é atraente, e os produtos engenheirados possuem grande potencial para a reparação de defeitos ósseos resultantes de traumas, ressecção cirúrgica e correções de deformidades congênitas (Salgada et al., 2004; Porter et al., 2009).

O Bioglass ${ }^{\circledR} 45 \mathrm{~S} 5$, um vidro contendo $\mathrm{SiO}_{2}-\mathrm{Na}_{2} \mathrm{O}-\mathrm{CaO}-\mathrm{P}_{2} \mathrm{O}_{5}$, está recebendo atenção considerável como material de scaffolds para a reparação do tecido ósseo e regeneração, principalmente por causa de sua excelente bioatividade, biocompatibilidade osteogênica e por apresentar efeito angiogênico (Rahaman et al., 2011). Tem sido demonstrado que o Bioglass ${ }^{\circledR}$ promove o aumento da secreção do fator de crescimento endotelial vascular (VEGF) in vitro e aumenta a vascularização in vivo, sugerindo que scaffolds contendo concentrações controladas de Bioglass ${ }^{\circledR}$ podem estimular a neo-vascularização, o que é benéfico para construção de tecidos engenheirados (Day et al., 2004).

O objetivo desse trabalho é produzir um compósito de hidrogel de celulose bacteriana incorporada com vidro bioativo, e analisar e caracterizar o biomaterial para possível uso na substituição e regeneração de tecidos ósseos.

\section{MATERIAIS E MÉTODOS}

\subsection{Produção de hidrogéis de celulose bacteriana}

A produção das membranas de celulose bacteriana foi feita no Laboratório de Tecnologias Integradas da Universidade Federal de Santa Catarina. Uma solução contendo a bactéria Gluconacetobacter hansenii ATCC 23769 foi mantida em placas de 24 poços durante 7 dias em cultura estática. O meio utilizado para a cultura dos hidrogéis foi o MANITOL, com pH ajustado a 6,5 e isento de quaisquer partículas de biovidro.

Os hidrogéis foram purificados através de uma solução de $\mathrm{NaOH} 0,1 \mathrm{M}$ pelo período de 24 horas a $50{ }^{\circ} \mathrm{C}$ e em seguida lavados com água destilada. Após purificadas as membranas permaneceram em água destilada.
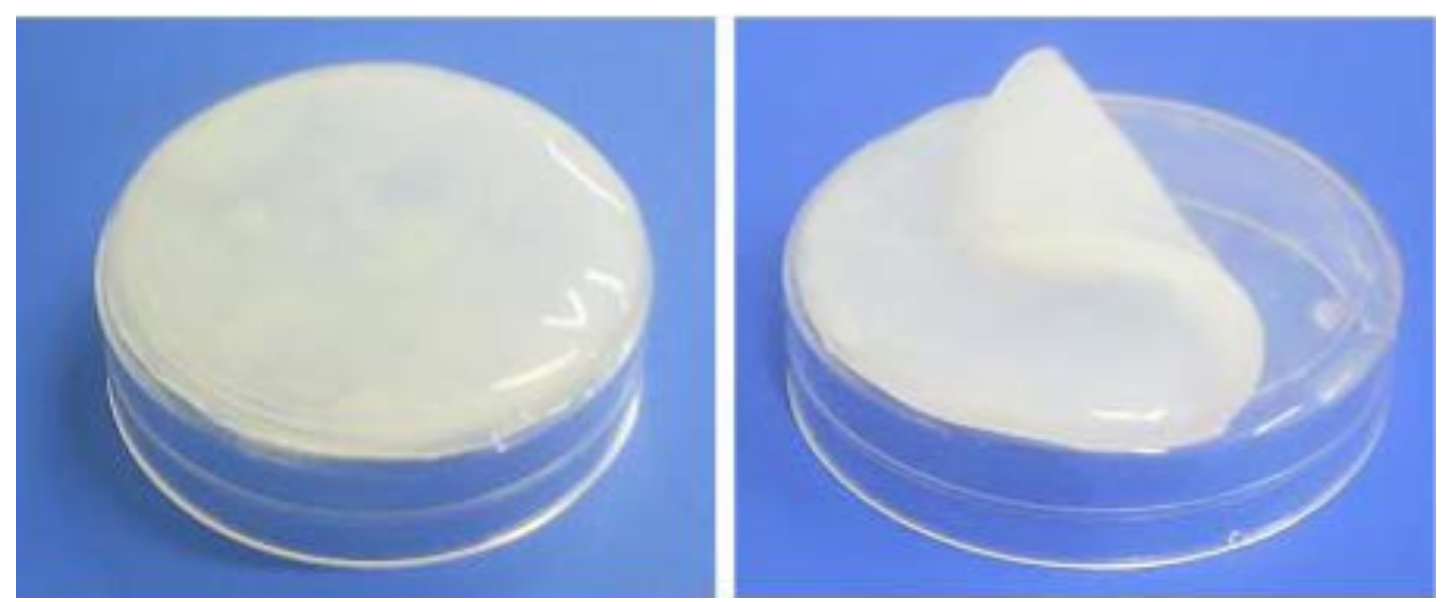

Figura 1- Membrana de hidrogel de celulose bacteriana produzida por G. hansenii em condições estáticas (Recouvreux, 2008). 


\subsection{Preparação dos compósitos CB-biovidro}

No Instituto de Biomateriais (WW7) da Universidade de Erlangen-Nuremberg (Alemanha), aos hidrogéis de celulose bacteriana produzidos e purificados, foram incorporadas micropartículas de biovidro (45S5 Bioglass ${ }^{\circledR}$, Alemanha) de tamanho médio igual a 2,0 $\mu \mathrm{m}$. Para a incorporação, foram suspensas juntamente com membranas circulares de celulose bacteriana (CB) três soluções, água destilada, 25\% e $50 \%$ de etanol em água com Bioglass ${ }^{\circledR} 45 \mathrm{~S} 5\left(1 \mathrm{~g} \cdot \mathrm{L}^{-1}\right)$. A solução permaneceu em agitação a $360 \mathrm{rpm}$ e temperatura ambiente, durante 6 e 24 horas, visando sua integração à matriz do hidrogel de celulose bacteriana.

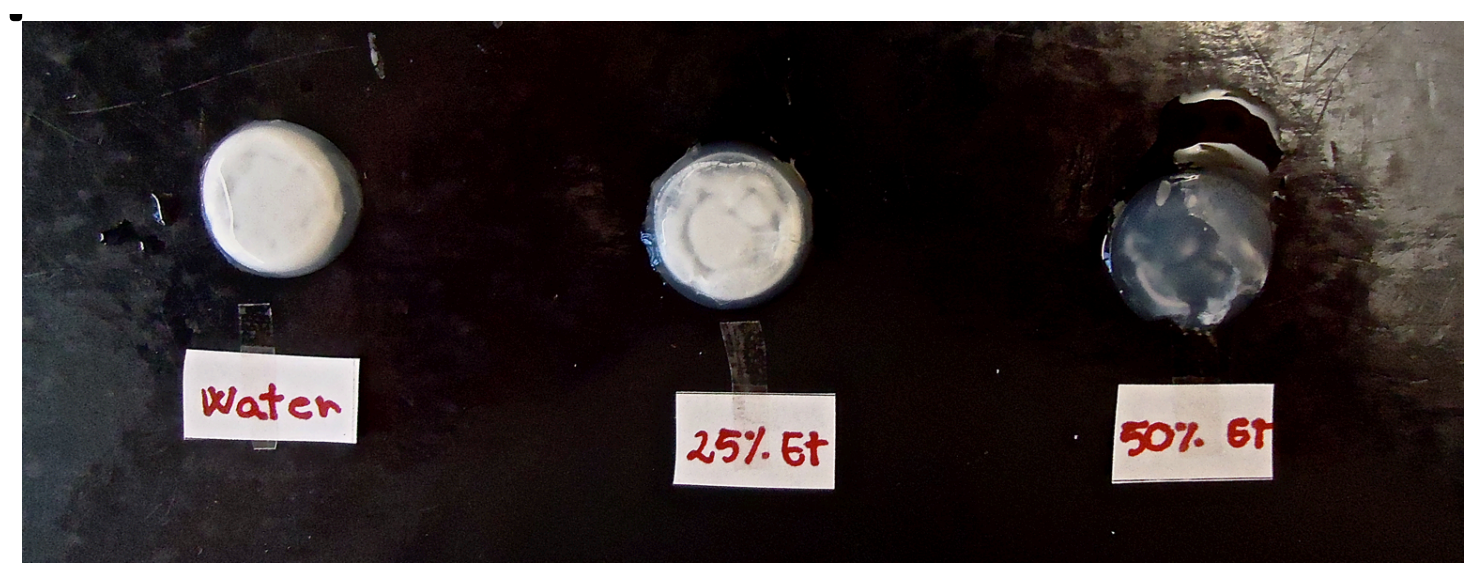

Figura 2 - Hidrogéis de celulose bacteriana após 24 horas, em soluções contendo biovidro em água (water), e em $25 \%$ e $50 \%$ de etanol em água.

\subsection{Caracterização dos compósitos formados}

As amostras já incorporadas com o biovidro foram caracterizadas e analisadas em microscópio eletrônico de varredura (MEV). Para a determinação das concentrações dos compósitos de celulose bacteriana incorporada com biovidro foi utilizado um espectrofotômetro de infravermelho com transformada de Fourier.

Os hidrogéis foram lavados com água destilada e desidratados com séries de soluções de etanol $(30 \%, 50 \%, 60 \%, 70 \%, 80 \%, 90 \%, 100 \%)$, por quinze minutos a cada lavagem. $\mathrm{O}$ procedimento utilizado para secagem das amostras foi pelo ponto crítico de $\mathrm{CO}_{2}$.

\section{RESULTADOS E DISCUSSÃO}

Como é possível observar visualmente (Ver Figura 2), diferentes quantidades de partículas de biovidro foram incorporadas nos hidrogéis.

As análises de MEV, conforme Figuras 3, 4 e 5, mostram a membrana de CB e a mesma com partículas incorporadas com biovidro. 


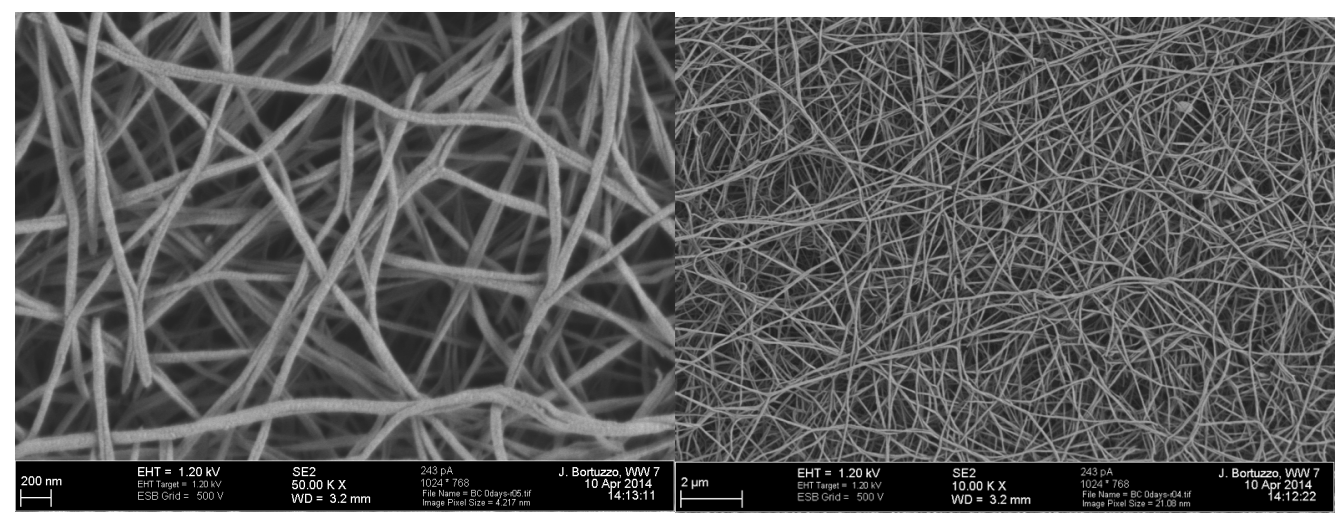

a)

b)

Figura 3 - Fibras do hidrogel de celulose bacteriana com aumento de a) $50.000 \times$ e b) $10.000 \times$.

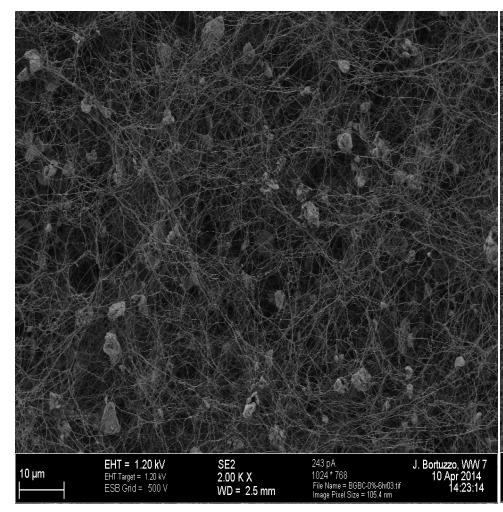

a)

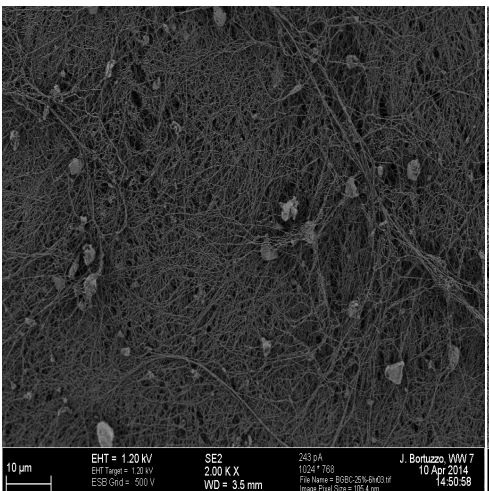

b)

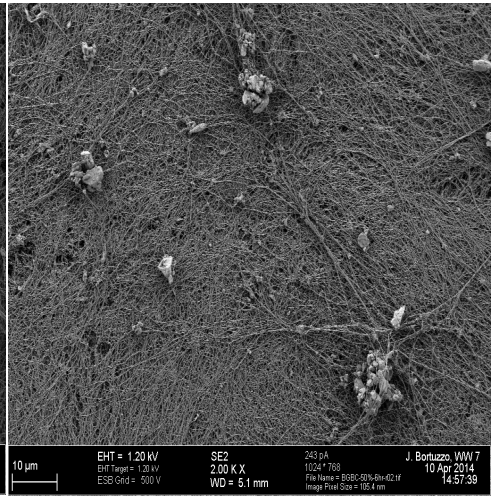

c)

Figura 4 - Comparação dos compósitos $\mathrm{CB}+$ Bioglass ${ }^{\circledR}$ 45S5 após 6 horas. Suspensão em: a) água, b) 25\% etanol em água, c) 50\% etanol em água.

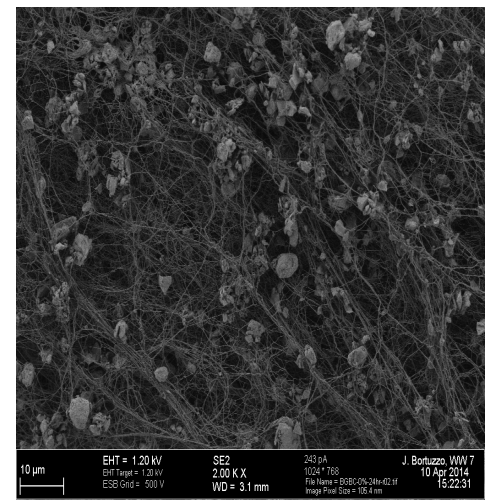

a)

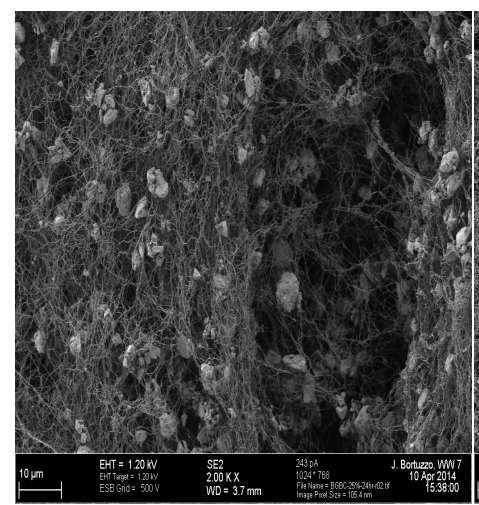

b)

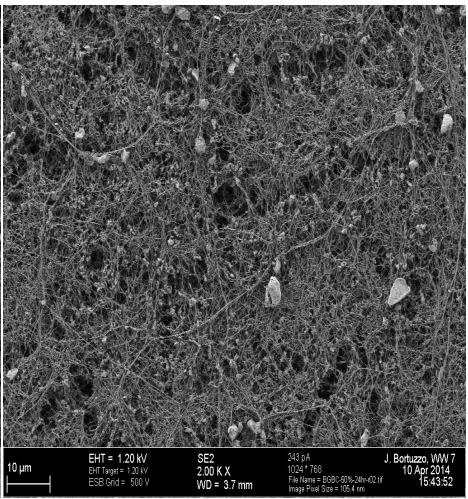

c)

Figura 5 - Comparação dos compósitos CB+Bioglass ${ }^{\circledR} 45 \mathrm{~S} 5$ após 24 horas em cultura agitada. Suspensão em: a) água, b) 25\%etanol em água, c) 50\% etanol em água

Pode-se observar uma deposição homogênea em todas as amostras. Porém, quanto maior a fração alcoólica da solução, menor a incorporação de partículas de biovidro. A combinação das propriedades da celulose bacteriana com as do biovidro pode permitir a modulação da bioatividade, biocompatibilidade osteogênica e efeito angiogênico. 
As Figuras 6 e 7 mostram, respectivamente, a caracterização por MEV e FTIR.

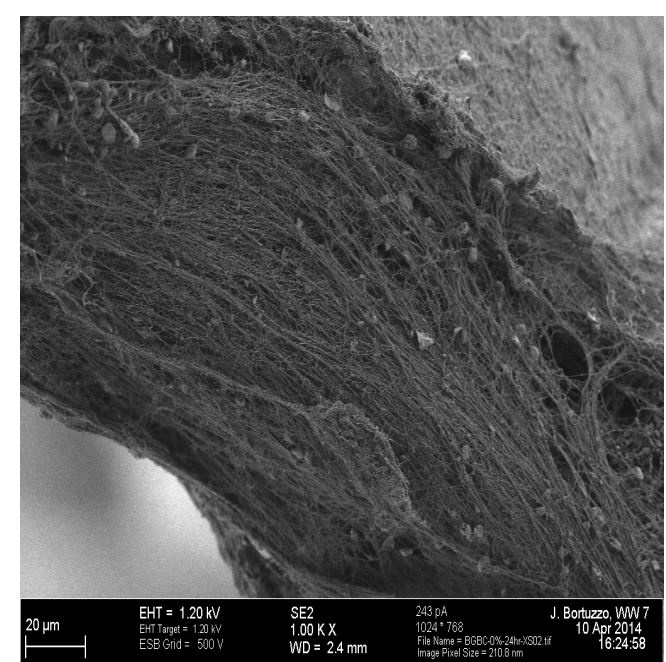

a)

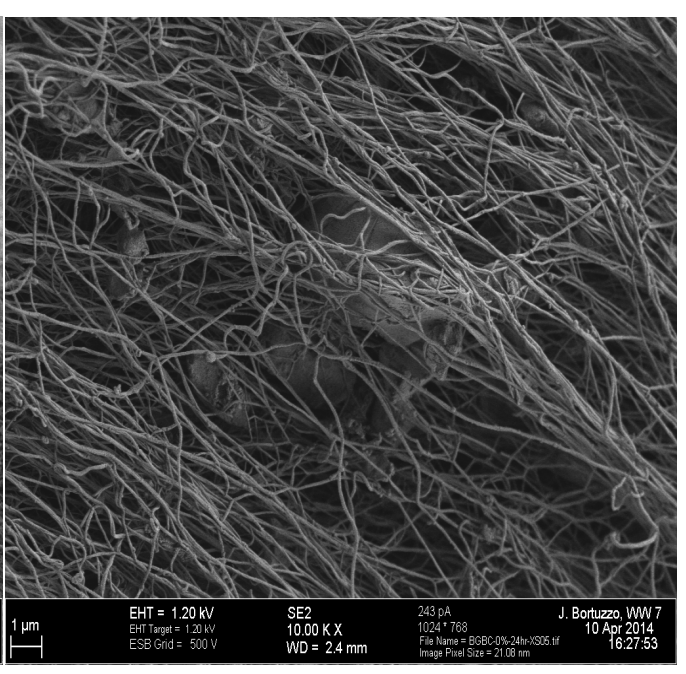

b)

Figura 6 - a) Imagem de um corte transversal do compósito de CB+Bioglass ${ }^{\circledR}$ 45S5. b) Partícula de biovidro entre as fibras da membrana de celulose bacteriana.

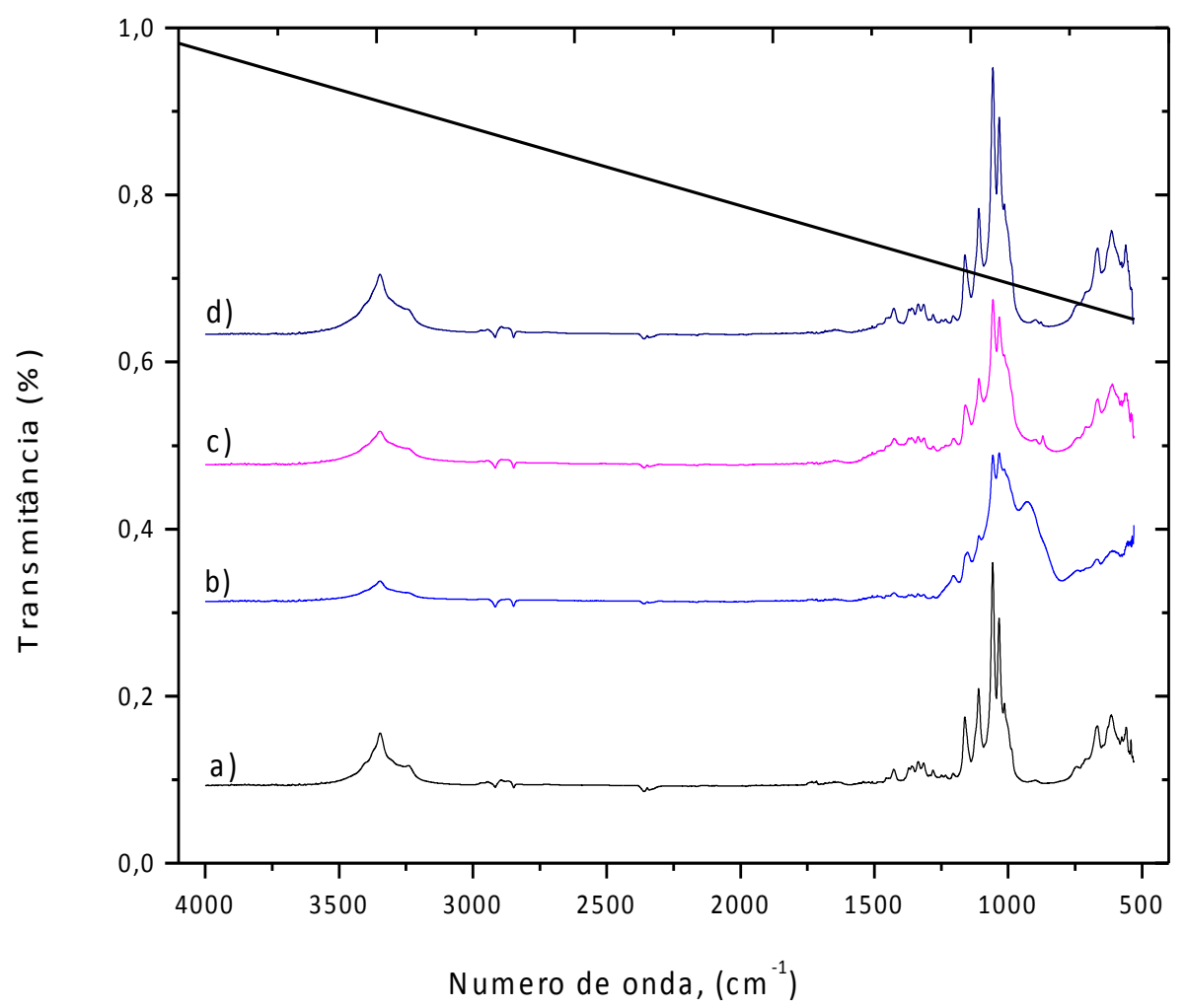

Figura 7 - Perfis de transmitância na região do infra-vermelho. a) Celulose bacteriana, referência; Compósito após suspensão em: b) água; c) em solução de $25 \%$ de etanol, e d) em solução de $50 \%$ de etanol. 
De acordo com a Figura 7 as amostras de CB e CB+Bioglass ${ }^{\circledR}$ em solução de $50 \%$ etanol apresentam picos similares, mostrando a pouca concentração de biovidro na membrana em solução alcoólica. Já na análise do compósito após 24 horas em solução contendo apenas água destilada, o FTIR sugere uma maior incorporação de biovidro, que segundo Mackovic et al. (2012), mostra que a banda de ocorrência de Bioglass ${ }^{\circledR}$ no espectro encontra-se na região de 930 a $1050 \mathrm{~cm}^{-1}$.

\section{CONCLUSÕES}

$\mathrm{Na}$ incorporação de partículas de Bioglass ${ }^{\circledR}$ 45S5 em membranas de celulose bacteriana obteve-se uma dispersão homogênea e a fixação das micropartículas de biovidro, apropriadamente encapsuladas no interior do hidrogel. Os melhores resultados foram obtidos após 24 horas em agitação e imersão em líquido contendo apenas água. Com a encapsulação de partículas de biovidro o biomaterial compósito poderá ser futuramente explorado para diversas aplicações como scaffold para engenharia $\mathrm{e}$ regeneração de tecidos ósseos.

\section{REFERÊNCIAS}

CHAN, G.; MOONEY, D.J. New materials for tissue engineering: towards greater control over the biological response. Trends Biotechnol. 26, p. 382-392, 2008.

DAY, R.M.; BOCCACCINI, A.R.; SHUREY, S.; ROETHER, J.A.; FORBES, A.; HENCH, L.L. et al. Assessment of polyglycolic acid mesh and bioactive glass for soft-tissue engineering scaffolds. Biomaterials, 25, p. 5857-5866, 2004.

DROTLEFF, S.; LUNGWITZ, M.; BREUNIG, A. Dennis, T. Blunk, J. Tessmar. Biomimetic polymers in pharmaceutical and biomedical sciences. Eur. J. Pharm. Biopharm., 58, p. 385-407, 2004.

KIM, H.W.; KNOWLES, J.C.; KIM, H.E. Hydroxyapatite/poly([epsilon]caprolactone) composite coatings on hydroxyapatite porous bone scaffold for drug delivery. Biomaterials, 25. p. 1279-1287, 2004.

LANGER, R.; VACANTI, J.P., Tissue engineering. Science, 260, p.920-926, 1993.

MACKOVIC, M.; HOPPE, A.; DETSCH, R.; MOHN, D.; STARK, W.J.; SPIECKER,E.; BOCCACCINI, A.R.. Bioactive glass (type 45S5) nanoparticles: in vitro reactivity on nanoscale and biocampability. J Nanopart Res. p 8. 2012

MANO, J.F.; SOUZA, R.A.; BOESEL, L.F.; NEVES ,N.M.; REIS, R.L., Biodegradable and injectable polymeric matrix composites for hard tissue replacement: state of the art and recent developments. Compos. Sci. Technol., p. 789$817,2004$.

PORTER, J.R.; RUCKH, T.T.; POPAT, K.C. Bone tissue engineering: a review in 
bone biomimetics and drug delivery strategies. Biotechnol. Prog., 25, p. 1539-1560, 2009.

RAHAMAN, M.N.; DAY, D.E.; SONNY BAL, B.; FU, Q.; JUNG, S.B.; BONEWALD, L.F. et al. Bioactive glass in tissue engineering. Acta Biomater., 7. p. 2355-2373, 2011.

RECOUVREUX, D.O.S.. Desenvolvimento de Novos Biomateriais Baseados em Celulose Bacteriana para Aplicações Biomédicas e de Engenharia de Tecidos. Tese de Doutorado, Programa de Pós-Graduação em Engenharia Química da Universidade Federal de Santa Catarina, 2008.

SALGADA, A.J.; COUTINHO, O.P., REIS, R.L. Bone tissue engineering: state of the art and future trends. Macromol Biosci, 4. p. 743-765, 2004.

SVENSSON, A.; NICKLASSON, E.; HARRAH, T.; PANILAITIS, B.; KAPLAN, D. L.; BRITTBERG, M.; GATENHOLM, P. Bacterial cellulose as a potential scaffold for tissue engineering of cartilage. Biomaterials, v.26, n.4, p. 419-431, 2005. 